Department of Economics - FEA/USP

\title{
Competitive Exchange Rate and Public Infrastructure in a Macrodynamic of Economic Growth
}

\section{ANTONIO SOARES MARTINS NETO GILBERTO TADEU LIMA}

WorkING PAPER SERIES № 2015-20 
DEPARTMENT OF ECONOMICS, FEA-USP

WORKING PAPER № 2015-20

\title{
Competitive Exchange Rate and Public Infrastructure in a Macrodynamic of Economic Growth
}

\author{
Antonio Soares Martins Neto (martinsneto.as@usp.br) \\ Gilberto Tadeu Lima (giltadeu@usp.br)
}

\begin{abstract}
:
We develop a dual open-economy model which incorporates a flow of public infrastructure as a factor of production to investigate effects of a competitive exchange rate policy under different levels of provision of public infrastructure. It is suggested that an exchange rate policy coordinated with a public infrastructure policy should produce better results. By increasing productivity in the tradable sector and by reducing inflationary pressures, this supply-side public policy contributes to the success of an economic growth strategy led by a competitive currency.
\end{abstract}

Keywords: Exchange rate policy; public infrastructure; economic development.

JEL Codes: H54; 041; 024. 


\section{Competitive exchange rate and public infrastructure in a macrodynamic of economic growth}

We develop a dual open-economy model which incorporates a flow of public infrastructure as a factor of production to investigate effects of a competitive exchange rate policy under different levels of provision of public infrastructure. It is suggested that an exchange rate policy coordinated with a public infrastructure policy should produce better results. By increasing productivity in the tradable sector and by reducing inflationary pressures, this supply-side public policy contributes to the success of an economic growth strategy led by a competitive currency.

Keywords: Exchange rate policy, public infrastructure, economic development.

J.E.L. Classification Codes: H54, O41, O24. 


\section{Introduction}

Within a developmental approach, a competitive, undervalued exchange rate appears as a key factor to foster economic growth. Although there is not a consensus about the channel through which the exchange rate interacts with growth - by the alleviation of the balance-of-payment constraints, increase in aggregate savings and investment (see Glüzmann et al., 2012; Razmi et al., 2012a), or gains in productivity in the tradable sector (for example, Rodrik, 2008) - , recent empirical studies found robust evidence that a competitive exchange rate positively affects economic growth.

Rodrik (2008), observing that an exchange rate devaluation stimulates growth, finds evidence that these results are especially valid for developing countries. Razmi et al. (2012b) find that currency devaluation is a major inducer of investment, with the evidence suggesting that the effect of undervaluation is larger and more robust for developing economies. Several other studies reinforce the role of competitive exchange rates in episodes of growth (e.g., Hausman et al., 2005; Gala, 2008; Razmi et al., 2012a) and exchange overvaluation as responsible for episodes of stagnation (Johnson et al., 2006).

Recent episodes of sustainable growth experienced by Korea, Taiwan, Singapore and, most recently, China, corroborate the role of a competitive exchange rate as inducer of growth. Similarly, countries that sustained their currency overvalued have experienced low growth trajectories, as were the cases of Brazil and Argentina during the 1990s (ECLAC, 2001). 
Additionally to the aforementioned empirical results, the theoretical literature has more recently focused on aspects related to the coordination of policies that influence the feasibility of a growth strategy led by a competitive exchange rate, the effect of exchange rate policy in an environment of heterogeneous preferences on the exchange rate, and the importance of the tradable sector for the success of this strategy.

The importance of the tradable sector is analyzed in Rodrik (2008). After empirically verifying the positive relationship between episodes of growth led by competitive exchange rates and capacity expansion of the tradable sector, the author builds a formal model that evaluates the process. Rodrik assumes that in developing countries the tradable sector suffers disproportionately from existing distortions, and an exchange rate policy is a way to compensate such disturbances. Developing countries achieve better results when they are able to alter relative profitability in favor of the tradable sector, especially industry.

Lima and Porcile (2013) use a dynamic model of capacity utilization and growth - where agents have heterogeneous preferences regarding the real exchange rate - to investigate how the latter is related to the functional income distribution and aggregate demand. By incorporating interclass and intraclass conflicts over the preferred real exchange rate, the authors incorporate the possibility of a contractionary devaluation. A competitive exchange rate policy can lower the share of wages in income and reduce aggregate demand, capacity utilization and economic growth. 
Rapetti (2013) uses a dual economy model to explore how aggregate demand and its effect on inflation can block the growth response of an exchange rate policy. Within the proposed framework, currency devaluation changes the relative profitability of the tradable sector, which is characterized by increasing returns. Particular attention is given to the inflationary pressures from non-tradables and wages, which may prevent the tradable sector from developing. The author concludes that policies' coordination, especially on domestic demand and wage growth, makes the strategy more viable.

However, the literature on competitive exchange rate and economic growth has paid scant attention to the importance of supply-side policies. The existence of an appropriate production structure, especially concerning infrastructure, is essential to promoting sustainable growth. Nurkse (1953), Rosenstein-Rodan (1957), and Hirschman (1961), for instance, emphasized the important role of infrastructure in the emergence of supply-side externalities and the enhancement of other activities. Lewis (1979), in his Nobel Prize lecture, highlighted that "growth requires physical infrastructure and trained manpower even when its purpose is only to export primary produce". In recent contributions, Barro (1990), Turnovsky and Fisher (1995), Agénor (2012), and Glomm and Ravikumar (1994) theoretically investigated the positive effects of public spending on infrastructure. In fact, several empirical studies found evidence of such positive effects, such as Aschauer (1989a and 1989b), Munnel (1992), Gramlich (1994), and Rivas (2003).

In recent years, however, provision of and investment in public infrastruc- 
ture has been reduced in many developing countries, mostly Latin American economies (see for example Perrotti and Sánchez, 2011). This increasing gap in public infrastructure has affected the productivity of these countries and accounted for a considerable part of the increasing output gap in Latin America, relative to Asian and developed countries (Calderón and Servén, 2003).

Along with a decreasing provision of and investment in public infrastructure, the debate about the importance of a competitive exchange rate has become more intense in those countries. Understood as a key determinant of international competitiveness, an undervalued exchange rate is frequently considered as a policy to trigger a process of rapid growth. Even though the issue of international competitiveness includes several aspects, the focus on the exchange rate has sometimes been disproportionate, which may compromise its success. Within a process of rapid development, several other circumstances and policies are likely to affect the path of an economy.

This paper contributes to the existing literature on competitive exchange rate and growth by investigating, by means of a theoretical model, some effects of exchange rate policy in environments characterized by different levels of provision of and investment in public infrastructure. While Rapetti (2013) (from which the model herein draws a great deal), which in turn is based on Ros and Skott (1998), focuses on the importance of conducting an exchange rate policy along with aggregate demand policies, we aim to explore some channels through which a supply-side policy can facilitate the success of a 
competitive exchange rate policy. It is suggested that the complementarity between an exchange rate policy and a public infrastructure policy may generate better growth performance. By increasing productivity in the tradable sector through provision of and investment in public infrastructure, the economy may require a lower devaluation in order to start an acceleration of growth, which reduces the extent of exchange rate pass-through consequences. At the same time, enhanced productivity in the non-tradable sector increases its supply of goods, which prevents domestic inflation from eroding the external competitiveness of the economy.

The remainder of the paper is organized as follows. Section 2 describes the structure of the model, while Section 3 analyses its dynamic behavior. Section 4 analyses the coordination of infrastructure and exchange rate policies. The paper closes with a summary of the main conclusions derived along the way.

\section{Model}

Consider a small open economy with two sectors, tradable (T) and nontradable $(\mathrm{N})$, populated by three types of agents: households, firms and government. The economy is open to trade and finance, and since the exchange rate is credibly fixed ${ }^{1}$, the interest parity condition imposes that:

\footnotetext{
${ }^{1}$ In the context of fixed exchange rates in which surprise devaluations may increase output, credibility becomes an essential attribute. When the outcome of a devaluation is likely to be expansionary, credibility will be assured only if policymakers are significantly concerned with inflation. Our assumption, therefore, implies that the government's commitment to avoid inflation is credible enough in the eyes of the market participants.
} 


$$
i=i^{*}
$$

where $i$ is the domestic interest rate and $i^{*}$ is the international one. This assumption also implies that as the balance of payments always adjust to imbalances in the current account, the external balance is not explicitly modeled. For simplicity, population (which is equal to the available labor force) is assumed to remain constant:

$$
L=L_{T}+L_{N}+U
$$

where $L_{T}$ and $L_{N}$ are the labor force employed in the tradable sector and non-tradable sector, respectively, and $U$ is unemployment. The tradable sector operates with a production function with increasing returns:

$$
Y_{T}=G^{\chi} K^{\alpha} L_{T}^{1-\alpha}
$$

where $\alpha \in(0,1)$ and $\chi \in(0,1), K$ is the private capital stock, $G$ denotes non-tradable public infrastructural goods and services provided without user charges by the government and $L_{T}$ is the corresponding labor input. Therefore, these public infrastructural goods and services increases the productive capacity available to the tradable sector. Unlike Agénor and Canuto (2012), for instance, we do not distinguish between basic and advanced infrastructure. However, it is likely that within a process of development, 
more advanced infrastructure is prioritized. In order to maintain simplicity, analytical tractability and focus on the general importance of the provision of infrastructure for growth, public infrastructure is defined herein as a flow of goods and services. Conceptually speaking, following Barro (1990), it is satisfactory to specify the government as provider of public infrastructure as doing no production and owning no capital. More precisely, we simplify matters by assuming that the government only buys a flow of output (which includes services of highways, airports, sewers, communication systems, etc.) from the private sector. The government then makes these purchased goods and services readily available to firms free of charge, with such provision of public infrastructure corresponding to the input that matters for private production. $^{2}$

As in Park and Philippopoulos (2004), we assume that the government taxes the firms' capital stock carried over from the previous period. More precisely, taxes are levied on the stock of capital (as a measure of the stock of wealth) instead of the flow of profit income. The government taxes the capital stock of the tradable sector at a constant rate $\tau \in(0,1)$ and its budget constraint is given by:

\footnotetext{
${ }^{2}$ As further remarked by Barro (1990), provided that the government and the private sector share the same production functions, the qualitative results would be the same if the government purchases private inputs and carries out its own production, instead of buying only final output from the private sector. Public infrastructure is also parsimoniously modeled as a flow variable, for instance, in Rivas (2003), Ohdoi (2007) and Agénor (2007). Meanwhile, public infrastructure is modeled as a stock variable, for instance, in Futagami et al. (1993) and Turnovsky (2004). In the model set forth in this paper, the modeling of public infrastructure as a stock variable would complicate matters considerably by adding an extra state variable, which would outweigh the corresponding analytical gains.
} 


$$
G=\tau K
$$

Using equation (4), equation (3) can be rewritten as:

$$
Y_{T}=\tau^{\chi}(1-\tau)^{\alpha} K^{\alpha+\chi} L_{T}^{1-\alpha}
$$

The price of the traded good is internationally determined:

$$
P_{T}=E P_{T}^{*}
$$

where $E$ is the nominal exchange rate, defined as the price of the foreign currency in terms of the domestic currency, $P_{T}$ is the domestic price, and $P_{T}^{*}$ is the foreign price.

Given the stock of capital and the wage, and assuming atomistic competition and hence price-taking behavior, the representative firm in the tradable sector exerts a demand for labor at any moment by standard profitmaximizing criteria:

$$
L_{T}=(1-\tau) \tau^{\frac{\chi}{\alpha}}\left[\frac{(1-\alpha)}{w_{T}}\right]^{\frac{1}{\alpha}} K^{\frac{\chi+\alpha}{\alpha}}
$$

where $w_{T} \equiv \frac{W}{P_{T}}$ is the tradable product wage and $\mathrm{W}$ is the nominal wage.

As the public infrastructural input is external to firm's decisions, profits in the tradable sector can be obtained by substituting (7) into the first order condition of the choice of the demand for capital: 


$$
r=\alpha(1-\tau) \tau^{\frac{\chi}{\alpha}} K^{\frac{\chi}{\alpha}}\left[\frac{1-\alpha}{w_{t}}\right]^{\frac{1-\alpha}{\alpha}}
$$

The non-traded good is produced under conditions of non-increasing returns and its price is locally determined. Assuming a typically low capital intensity in this sector, we consider a simple production function with labor as the only input. As a first approximation, we neglect the effects of public infrastructure in the non-tradable sector to facilitate the understanding of the various effects of this supply-side policy. Later on this assumption will be relaxed and the effect of public infrastructure in this sector will be considered. Formally:

$$
Y_{N}=B L_{N}^{\sigma}
$$

where $B$ is a fixed factor and $\sigma \in(0,1)$. The demand for labor in this sector arises from profit maximization by the owners of the fixed factor. Hence:

$$
L_{N}=\left[\frac{\sigma B}{w_{N}}\right]^{\frac{1}{1-\sigma}}
$$

where $w_{N} \equiv \frac{W}{P_{N}}$ is the non-tradable product wage.

Considering a Cobb-Douglas utility function, consumers maximize consumption such that the relative private consumption is: 


$$
\frac{C_{T}}{C_{N}}=\frac{\phi}{1-\phi}\left(\frac{P_{N}}{P_{T}}\right)
$$

where $\phi \in(0,1)$ and $1-\phi$ are the share of consumers' income spent on tradable and non-tradable goods, respectively.

For simplicity, we assume that workers do not save while capitalists in the tradable sector and owners of the fixed factor in the non-tradable sector save a common and exogenously given constant fraction $s$ of their profits and rents, respectively. In fact, our main qualitative results are unaffected by this simplifying assumption. We can set the following goods market equilibrium condition:

$$
P_{N} C_{N}+P_{T} C_{T}=W\left(L_{T}+L_{N}\right)+(1-s) r(1-\tau) K P_{T}+(1-s) \Pi_{N}
$$

where $\Pi_{N}$ are the rents of the owners of the fixed factor B. Since we do not distinguish between importables and exportables, depending on the balance between domestic production and demand, the country either will be an exporter or importer of the traded good. Also, since non-tradables are used only for domestic consumption, the market equilibrium condition requires that output equal expenditure:

$$
Y_{N}=C_{N}
$$




\section{Dynamic Behavior}

The (net) rate of capital accumulation is assumed to vary positively with the excess of the profit rate over the cost of finance given by $i$, and negatively with the rate of depreciation, $\delta$ :

$$
\hat{K}=r-(i+\delta)
$$

where a hat $\left({ }^{\wedge}\right)$ represents proportionate rates of growth. ${ }^{3}$ Note that domestic savings need not equal domestic investment, as determined by equation (14). It is assumed, therefore, that capital is internationally mobile.

Substituting (8) into (14), we have:

$$
\hat{K}=\alpha(1-\tau) \tau^{\frac{\chi}{\alpha}} K^{\frac{\chi}{\alpha}}\left[\frac{1-\alpha}{w_{T}}\right]^{\frac{1-\alpha}{\alpha}}-(i+\delta)
$$

Wages are defined through a bargaining process between workers (from both sectors and with the same aspirations) and capitalists, which is represented by workers' demand for a desired wage. Workers demand wages as a result of both expectations about inflation and the difference between the prevailing wage and the desired one, according to the following expression (Porcile and Lima, 2010):

\footnotetext{
${ }^{3} \mathrm{~A}$ possible extension of the model is to reasonably assume that the rate of depreciation of the physical capital stock varies endogenously with the flow of provision of and investment in public infrastructure. In the simple case in which depreciation is a linear and negative function of the flow of public infrastructure, this extension does not change the following qualitative results, though.
} 


$$
\hat{W}=\frac{w^{d}-w}{w}+\hat{P}^{E}
$$

where $w^{d}$ is workers' desired real wage, $\frac{W^{d}}{P}, w=\frac{W}{P}, P=P_{T}^{\phi} P_{N}^{1-\phi}$ and the superscript $E$ means "expected". The desired wage is defined endogenously as a result of variations in the rate of employment:

$$
w^{d}=m(1-e)^{-\xi}
$$

where, assuming $L=1, e$ is the rate of employment $\left(L_{T}+L_{N}\right), \xi \in(0,1)$, and $m$ is a positive constant which reflects labor market regulations (such as collective negotiations, degree of unionization, unemployment benefits, and minimum wages). For instance, a higher (lower) minimum wage increases (decreases) the desired wage.

Price expectation is given by the weights of tradable and non-tradable prices in the private consumption basket. As $E$ is fixed and assuming that $\hat{P}_{T}$ $=0$, expected inflation (which is assumed to be equal to the actual inflation rate) is proportional to non-tradable prices inflation:

$$
\hat{P}^{E}=(1-\phi) \hat{P}_{N}
$$

As $P_{N} \equiv \frac{W}{w_{N}}$, we have:

$$
\hat{P}_{N}=\hat{W}-\hat{w}_{N}
$$


Substituting from equations (16)-(19), we have (see appendix A):

$$
\hat{W}=\frac{1}{\rho \phi}\left\{\frac{w^{d}-w}{w}-(1-\phi)\left[\frac{(\alpha+\chi)(\sigma-1)}{\alpha} \hat{K}\right]\right\}
$$

where $\rho \equiv\left[1-\frac{(1-\phi)(\sigma-1)}{\phi \alpha}\right]>0$.

From (15) is clear that $\hat{K}$ increases with $K$ and falls with $w_{T}$, so that we need to focus on the first term in the right-hand side of $(20) .{ }^{4}$ We know from (22) and (7) that $L_{T}$ and $L_{N}$ increase with $K$ and fall with $w_{T}$. Thus, the employment rate $e$ varies positively with $\mathrm{K}$ and negatively with $w_{t}$. Finally, we know from (30) that $w_{N}$ varies negatively with $\mathrm{K}$ and positively with $w_{T}$. As a result, the desired wage varies positively with $\mathrm{K}$ and negatively with $w_{T}$.

Equation (20) describes the response of wage growth to labor demand and capital accumulation. Consider the case of an exogenous rise in the tradable sector profitability (e.g., a fall in the cost of finance), which by equation (14) induces a rise in capital accumulation. A rise in capital accumulation (a rise in $K$ ) leads to a rise in labor demand by the tradable sector (a rise in $L_{T}$ ). This higher demand reduces the rate of unemployment (which in turn raises workers' desired wage by increasing their bargaining power) and reduces the relative size of the non-tradable sector workforce. A relative fall in the supply of non-tradable goods along with a rising demand for them (as total

\footnotetext{
${ }^{4} \mathrm{As} P_{T}$ is assumed constant, it follows that $\hat{W}=\hat{w}_{T}$ at any point in time. Therefore, we could specify the wage dynamics in terms of either $\hat{W}$ or $\hat{w}_{T}$. As suggested by one of the referees, however, representing the model in the product wage space is more in line with the treatment of nominal wages in the rest of the model.
} 
employment rises), leads to rising inflation. Therefore, capital accumulation is followed by rising prices and wages.

Equations (15) and (20) form a two-dimensional system of autonomous differential equations, which we present below in a reduced form. While the derivation of the $\hat{K}=0$ locus is straightforward, appendix B presents the derivation of the $\hat{w}_{T}=0$ locus. An important condition for multiple equilibria to occur is to have a relatively small effect of public infrastructure, otherwise the trajectory would be explosive (see appendix $\mathrm{C}$ for more details). Our subsequent discussion assumes that all conditions for multiple equilibria are met.

$$
\begin{gathered}
\hat{K}=f\left(K, w_{T} ; \tau\right) \\
\hat{w}_{T}=g\left(K, w_{T} ; \tau\right)
\end{gathered}
$$

where $f_{K}>0, f_{w_{T}}<0, g_{K}>0, g_{w_{T}}<0$.

Figure 1 shows the phase diagram with its three steady states, represented by equilibrium points A, B and C. Equilibrium point A is stable and defines a case of complete underdevelopment. Equilibrium point B is a steady state of relatively low stock of capital and, therefore, relatively low per capita income, while equilibrium point $\mathrm{C}$ has a relatively higher stock of capital. Equilibrium point B is a saddle point, with the positively sloped saddle path dividing the plane in two regions. To the left of the saddle path the behavior of the system is pushing the economy towards equilibrium point $\mathrm{A}$, while at 
any point to the right of the saddle path the economy is moving towards equilibrium point $\mathrm{C}$, which is stable. It is only in the case that the economy happens to be exactly in the saddle path that it will be moving towards equilibrium point B.

Figure 1 about here

\section{The role of exchange rate policy and the importance of public infrastructure}

\subsection{The role of exchange rate policy}

An exchange rate policy puts a downward pressure on real wages in the short-run, which promotes the expansion of the tradable sector via price incentives. In the medium run, this high profitability in the tradable sector promotes higher investment, which increases $K$. An increase in $K$ brings in a positive feedback through $G$, which induces a virtuous cycle between productivity increases and the desire to invest. However, as a result of this process, the absorption of workers by the tradable sector rises. This higher demand for labor by the tradable sector reduces the relative supply of nontradable goods and increases the bargaining power of workers, resulting in higher prices and wages. This subsequent rise in wages has a negative impact on the development process, and hence the possibility of a virtuous process depends on the forces of these ambiguous mechanisms.

Figure 2 shows a situation where a devaluation pushes the economy from 
point $\mathrm{X}$ to $\mathrm{Y}$. A devaluation (a rise in $E$ ) exerts a downward pressure in the product wage $\left(w_{T}=\frac{W}{P_{T}^{*} E}\right)$ for a given stock of capital, which in turn raises the tradable sector profitability. This process shifts an economy from a trajectory of underdevelopment to a trajectory towards equilibrium with relatively higher development (from the left side to the right side of the saddle path). This result is in accordance with the empirical literature (see Rodrik and McMillan, 2011) which shows that a competitive exchange rate policy induces a process of structural change (understood as a change towards sectors of higher productivity) in developing economies, and with the results found in Razmi et al. (2012b) and Rodrik (2008).

Figure 2 about here

Resource reallocation is the main driver of this process. In parts of Africa, for instance, where the employment share of agriculture is still significant, this process could be understood as a movement from agriculture towards industry. In Latin American countries where the share of low productivity services has been increasing, the shift could be mostly from services to manufacture. In both cases, the increase in total employment correlates with increases in the overall productivity of the economy, boosting employment, investment and growth.

But a feasible devaluation is not necessarily successful. Excessive devaluation might affect the credibility of the fixed exchange rate and, additionally, may be quickly reversed due to rapid pass-through on non-tradable prices 
and wages, which is in accordance with the results of Taylor et al. (2001). ${ }^{5}$ These asymmetries in terms of the size of the devaluation may result from "menu costs" associated with changing prices: small exchange rate variations can be absorbed by firms and only changes exceeding a threshold are passed through prices (see Aron et al., 2014, for a survey of studies on exchange rate pass through).

Figure 3 shows a case in which a feasible devaluation is not sufficient. Suppose a country situated at point $\mathrm{X}$, in the left side of the saddle path. A devaluation moves the economy to point Y. In contrast to the preceding case, despite an initial stimulus, the spur in capital accumulation and the productivity gains would not last long enough to induce a process of steady development. Our next step is to understand how different flows of public provision of infrastructure as a complementary policy to exchange devaluation can change this result.

Figure 3 about here

\subsection{The role of public infrastructure}

Suppose again an economy situated at point $\mathrm{X}$ and represented by the black

\footnotetext{
${ }^{5} \mathrm{~A}$ devaluation can alter the inflationary expectations of the market participants. If credibility is lost, private agents will expect that the Central Bank will deviate again from its exchange rate commitment, triggering an inflationary cycle. Additionally, in the case of significant inflationary pressures, a policy response (a further devaluation) may hinder the process, as pointed out by Rapetti (2013, p.18): "in a context in which nominal devaluations instead of generating a RER depreciation lead to rises in domestic prices, engaging in further devaluations is likely to accelerate the rate of inflation".
} 
isoclines in Figure 4. As in the previous case, a devaluation shifts this economy to point $Y$, still in the trajectory of total underdevelopment. Let us now assume that this economy raises the flow of public provision of infrastructure (a higher $\tau$ ). As we can see from equation (15), the rate of capital accumulation is an inverted U-shaped function in $\tau$ which, as it can be checked, has a maximum at $\tau=\frac{\chi}{\alpha+\chi}$. We assume herein that any change in $\tau$ takes place with $\tau$ remaining to the left of such maximum value. ${ }^{6}$ Thus, any increase in $\tau$ induces an upwards shift in the isocline $\hat{K}=0$.

Another important assumption concerns the shift in the $\hat{w}_{T}=0$ isocline, which also shifts upwards. A rise in the flow of public provision of infrastructure increases productivity and labor demand (per equation 7), which in turn rises workers' bargaining power (per equation 17). If the subsequent rise in real wages surpasses the former rise in productivity, the economy will continue trapped in a trajectory of underdevelopment (in the left side of the saddle path). In order to ensure that this shift does not eliminate the positive effect of $\hat{K}=0$, we must assume that the response of the desired wages

\footnotetext{
${ }^{6}$ In our setting, taxation favors tradable sector firms up to a maximum value. Under this assumption, there is not a political economy constraint to the setting of the tax rate, which raises two questions. The first one is why the private sector itself (which bears the burden of taxation alone) does not supply infrastructure, while the second question is why the government is not able to tax optimally. The former question can be answered by appealing to a typical free rider problem, in which the provision of a public good will not be optimal in the presence of free riders. As for the second question, a possible constraint that prevents the government from choosing the optimal tax is the existence of imperfect information, which is a plausible assumption for developing economies with poor data and a lack of skilled government officials. Under these circumstances, it is reasonable to assume that the government is not able to set the optimal tax rate. In a more inclusive model in which workers and owners of the fixed factor are taxed as well, admittedly, political economy constraints to the setting of the tax rate may be more likely to emerge.
} 
to a rise in employment $(\chi)$ is not too large and that the share of tradables in private consumption is sufficiently large, as already assumed earlier (see appendix C).

Figure 4 about here

Note that in this case point $\mathrm{Y}$ lies in the trajectory of higher development (in the right side of the new saddle path) and thus the feasible devaluation is sufficient to bring a process of development as a result of the complementarity between the exchange rate and public infrastructure policies. The intuition for the complementarity between these policies is straightforward. A higher flow of provision of public infrastructure provides higher productivity for the tradable sector, which then requires a lower devaluation in order to expand. An increase in $\tau$ provides a better productive environment for the economy, which increases production possibilities. In this new environment, the odds of an exchange rate policy succeeding are higher, and this is so also because a lower devaluation reduces the exchange rate pass-through to prices and wages, which could undo the positive impact of the currency devaluation.

On the other hand, the financing of public infrastructure is a challenge for most developing economies, especially in this environment. Rapetti (2013) shows how the implementation of domestic demand policies, including the reduction of government spending, can be important to accomplish a successful exchange rate policy. The right balance between types of expenditure must be found, opting for the reduction in non-productive expenditure. Moreover, 
a greater involvement of private investors can mitigate such problems. In this sense, the increasingly popular public-private partnership is a good prospect, as it can divert resources and efficiency patterns of the private sector to boost the financing of infrastructure. Additionally, as mentioned earlier, it is expected that in the process of development investment in advanced infrastructure is prioritized. In fact, the scarcity of investment of this type can lock an economy in a middle-income trap (see Agénor and Canuto 2012).

Even though we have focused on the complementarity of public infrastructure and exchange rate policies, we could also consider public infrastructure policy separately. In fact, the movement towards point $\mathrm{C}$ can be achieved through a higher flow of provision of public infrastructure, instead of a currency devaluation (see Figure 5). In this case, there is not a shift from $\mathrm{X}$ to $\mathrm{Y}$, but a shift upward of the isoclines $\hat{w}_{T}=0$ and $\hat{K}=0$, such that point $\mathrm{X}$ is now to the right of the saddle path and hence moving towards the long-run equilibrium with higher stock of capital. Similarly to the case of an insufficient devaluation, this upward movement can fail to affect positively the trajectory of the economy.

Figure 5 about here

The possibility of obtaining the same results through a public infrastructure policy leads one to wonder which one is the best policy. This is evidently a very broad question, which we can briefly discuss, for instance, from the perspective of the distribution of income. Both policies, when successful, 
lead to higher employment. However, there is a relevant difference in terms of distribution. Suppose that an economy opts for a devaluation (see Figure 3), shifting from $\mathrm{X}$ to $\mathrm{Y}$. Note that at this point, wages are lower, and the equilibrium with higher development remains at equilibrium point $\mathrm{C}$. In the case of a public infrastructure policy, however, the new relevant isoclines are the dotted red ones, so that the initial real wage is the same as before and the equilibrium with higher development has a higher real wage (see equilibrium point C' in Figure 4).

In other words, an important caveat to a competitive exchange rate policy is its impact on income distribution. A devaluation raises the price of imported goods, which in turn reduces real wages. On the other hand, in the present framework, the cost of public infrastructure is entirely paid by taxes levied on capitalists of the tradable sector, without any direct effect on real wages. In fact, as explored in the next section, given the rise in productivity caused by a rise in the supply of public infrastructure, non-tradable prices may fall and real wages rise. Hence, given the possibility of choosing between policies, a competitive exchange rate policy may be more likely to result in a lower wage share. In the case of complementarity between policies, the higher the flow of provision of public infrastructure (that is, the higher the tax rate), the higher the wage share. Moreover, from a political economy perspective, as the complementarity between policies reduces the burden of a real exchange rate devaluation on workers, its implementation may be facilitated. 


\subsection{Public infrastructure and inflation}

We have so far focused on the positive effects of an increase in the flow of provision of public infrastructure on the productivity of the tradables sector. As seen above, the complementarity of policies can result in a successful exchange rate policy, thus leading the economy to a path of development. However, an important consequence of an appropriate supply of public infrastructure is the impact on prices.

In order to preserve the simplicity and tractability of the model, let us make some further assumptions. In the baseline version, the flow of provision of public infrastructure does not participate as an input in the production of the non-tradable sector. In order to further our analysis and include some effects of public infrastructure on domestic prices, let us then assume an alternative production function for the non-tradable sector:

$$
Y_{N}=B G^{\eta} L_{N}^{\sigma}
$$

where $\eta<\chi$ and $\eta+\sigma<1$. All the other assumptions remain intact, so that we are dropping solely the assumption that public infrastructure does not participate as an input in the production of non-tradable goods. The assumption that $\eta$ is lower than $\chi$ is based on the fact that since the non-tradable sector does not use capital (or uses less capital, more realisti-

cally speaking), this sector benefits less from the flow of provision of public infrastructure. 
Figure 6 about here

The introduction of public infrastructure in the non-tradable sector changes the $\hat{w}_{T}=0$ isocline in two different ways. ${ }^{7}$ First, it changes the slope of the isocline, as represented in Figure 6 by the dashed red lines. This change is a consequence of a lower rate of inflation in the economy, since the process of development goes along with an increase in productivity of the non-tradable sector. Therefore, the relative supply of non-tradable goods falls at a slower pace during the migration of labor force to the tradable sector. This implies not only a dynamic of lower inflation, but also a stable long-run equilibrium with higher stock of capital.

The second effect occurs when we increase the tax rate, as discussed in the previous case of complementarity of policies. Even though both isoclines will move upward as represented in Figure 4, the shift in the $\hat{w}_{T}=0$ isocline is expectedly smaller. This result comes from the lower impact of $\tau$ on the intercept, since now part of its effect on domestic prices is positive.

The complementarity of public infrastructure is likely to include a broad range of services that favor both the tradable and non-tradable sectors. While public infrastructure is important to boost productivity in the tradable sec-

\footnotetext{
${ }^{7}$ We can solve the model in the same way, the only difference being that now the flow of provision of public infrastructure affects the demand for labor in the non-tradable sector and hence the slope of the $\hat{w}_{T}=0$ isocline. Mathematically, the difference is a change in equation (34), where the new condition for multiple equilibria is:
}

$$
\frac{\chi}{1-\alpha}>\frac{(\chi+\alpha) \phi(1-\sigma)-\phi \alpha \eta}{\alpha(1-\phi)+(1-\sigma) \phi}
$$

Note also that with a higher $\eta$ it is more likely that this condition will hold. 
tor, it is equally important to avoid a relatively lower supply of non-tradable goods resulting in inflationary pressures that erode international price competitiveness. Therefore, the process of development involves avoiding the rise of a dual economy with large differences in sectoral productivities.

\section{Conclusion}

As of late, a competitive exchange rate policy has been often claimed to be growth-enhancing. In fact, there is considerable empirical and theoretical support for such claims, including the relatively recent episodes of high growth experienced by Asian economies. However, the literature has paid insufficient attention to the possibility that the feasibility and success of an exchange rate policy as economic growth enhancer can be improved by its coordination with supply-side public policies.

This paper develops a dual economy model to explore the implications of different flows of provision of public infrastructure as complementary to a competitive exchange rate policy. In the model, an exchange rate devaluation favors the profitability in the tradable sector and bring the economy to the track of development. The government taxes the capital stock endowed by firms in the tradable sector and invests all the resulting tax collection in the provision of a flow of public infrastructure.

The model shows that (i) a higher flow of provision of public infrastructure

results in higher productivity in the tradable sector, so that a lower currency 
devaluation than otherwise is required to increase the economic growth rate; (ii) a higher flow of provision of public infrastructure leads to lower inflation in the economy, since the process of development goes along with an increase in productivity in the non-tradable sector, and (iii) when there is a choice between a competitive exchange rate policy and a public infrastructure policy, one relevant issue to consider is that the use of the latter is accompanied by an increase in the share of wages in income.

All in all, the prospects for a competitive exchange rate to be feasible, successful and sustainable as a growth-enhancing development policy are improved when such exchange rate policy is pursued in conjunction with a suitable complementary public infrastructure policy. 


\section{References}

Agénor, P-R. (2007): 'Fiscal policy and endogenous growth with public infrastructure', Oxford Economic Papers, 60, pp. 57-87.

Agénor, P-R. (2012): 'Infrastructure, public education and growth with congestion costs', Bulletin of Economic Research, 64(4), pp. 449-469.

Agénor, P-R., Canuto, O. (2012): 'Middle-Income Growth Traps', World Bank Policy Research Working Paper, 6210.

Aron, J., Macdonald, R., Muellbauer, J. (2014): 'Exchange Rate PassThrough in Developing and Emerging Markets: A Survey of Conceptual, Methodological and Policy Issues, and Selected Empirical Findings', The Journal of Development Studies, 50(1), pp. 101-143.

Aschauer, D. A. (1989a): 'Is Public Expenditure Productive?', Journal of Monetary Economics, 23(2), pp. 117-200.

Aschauer, D. A. (1989b): 'Public investment and productivity growth', Working Paper Series, Macroeconomic Issues, Federal Reserve Bank of Chicago, pp. 89-113.

Barro, R. (1990): 'Government spending in a simple model of endogenous growth', Journal of Political Economy, 98, pp. 103-125.

Calderón, C., Servén, L. (2003): 'The Output Cost of Latin America's Infrastructure Gap', in W. Easterly and Servén, L. (ed): The Limits of Stabilization: Infrastructure, Public Deficits and Growth in Latin America, Stan- 
ford University Press, Palo Alto.

ECLAC. (2001): Una Década de Luces y Sombras: América Latina y el Caribe en los Años Noventa, Alfaomega, Bogotá.

Futagami, K., Morita, Y., Shibata, A. (1993): 'Dynamic Analysis of an Endogenous Growth Model with Public Capital', Scandinavian Journal of Economics, 95(4), pp. 607-625.

Gala, P. (2008): 'Real exchange rate levels and economic development: theoretical analysis and econometric evidence', Cambridge Journal of Economics, 32(2), pp. 273-288.

Glomm, G., Ravikumar, B. (1994): 'Public investment in infrastructure in a simple growth model', Journal of Economic Dynamics and Control, 18(6), pp. 1173-1187.

Glüzmann, P. A., Levy-Yeyati, E., Sturzenegger, F. (2012): 'Exchange rate undervaluation and economic growth: Díaz Alejandro (1965) revisited', Economics Letters, 117(3), pp. 666-672.

Gramlich, E. (1994): 'Infrastructure Investment: A Review Essay', Journal of Economic Literature, 32(3), pp. 1176-1196.

Hausmann, R., Pritchett, L., Rodrik, D. (2005): 'Growth accelerations', Journal of Economic Growth, Springer, 10(4), pp. 303-329.

Hirschman, A. (1961): La estrategia del desarrollo económico. Yale University Press, New Haven. 
Johnson, S., Ostry, J., Subramanian, A. (2006): 'Levers for Growth: Policy Lessons from Earlier Bouts of Growth in Developing Countries', Finance and Development, 43(1), pp. 28-32.

Lewis, A. (1979): 'Lecture to the memory of Alfred Nobel', in Lindbeck, A. (ed) (1992): Nobel Lectures, Economics, World Scientific Publishing Co., Singapore [acessed on 10 Jun. 2015 from http://www.no belprize.org/nobel prizes/economic-sciences/laureates/1979/lewis-lecture.html]

Lima G.T., Porcile, G. (2013): 'Economic growth and income distribution with heterogeneous preferences on the real exchange rate', Journal of Post Keynesian Economics, 35(4), pp. 651-674.

Munnell, A. (1992): 'Policy watch: infrastructure investment and economic growth', The Journal of Economic Perspectives, 6(4), pp. 189-198.

Nurkse, R. (1953): Problems of Capital Formation in Underdeveloped Countries, Oxford University Press.

Ohdoi R. (2007): 'Productive government spending, patterns of specialization and economic growth in a small open economy', Japanese Economic Review, 58, pp. 127-146.

Park, H., Philippopoulos, A. (2004): 'Indeterminacy and Fiscal Policies in a Growing Economy', Journal of Economic Dynamics and Control, 28, pp. 645-660.

Perrotti, D., Sánchez, R. (2011): 'La brecha de infraestructura en América 
Latina y el Caribe', Recursos Naturales e Infraestructura Series, No. 153 (LC/L.33 42- P/E), Santiago, Chile, Economic Commission for Latin America and the Caribbean (ECLAC).

Porcile, G., Lima, G.T. (2010): 'Real exchange rate and elasticity of labour supply in a balance-of-payments-constrained macrodynamics', Cambridge Journal of Economics, 34(6), pp. 1019-1039.

Rapetti, M. (2013): 'Macroeconomic Policy Coordination in a Competitive Real Exchange Rate Strategy for Development', Journal of Globalization and Development, 3(2), pp. 1-31.

Razmi, A., Rapetti, M., Skott, P. (2012a): 'The real exchange rate and economic development', Structural Change and Economic Dynamics, vol. 23(2), pp. 151-169.

Razmi, A., Rapetti, M., Skott, P. (2012b): 'The Real Exchange Rate and Economic Growth: Are Developing Countries Different?', International Review of Applied Economics, 26(6), pp. 735-753.

Rivas, L. (2003): 'Income taxes, spending composition and long-run growth', European Economic Review, 47(3), 477-503.

Rodrik, D. (2008): 'The Real Exchange Rate and Economic Growth', Brookings Economic Studies Program, The Brookings Institution, 39(2), pp. 365-439.

Rodrik, D., McMillan, M. (2011): 'Globalization, Structural Change and 
Productivity Growth', NBER Working Papers 17143, National Bureau of Economic Research, Inc.

Ros, J., Skott, P. (1998): 'Dynamic Effects of Trade Liberalization and Currency Overvaluation under Conditions of Increasing Returns', The Manchester School, 66(4), pp. 466-489.

Rosenstein-Rodan, P.N. (1957): 'Notes on the Theory of the 'Big Push", in Ellis, H.S. and Wallic, H.C. (ed): Economic Development for Latin America, Macmillan, London.

Taylor, M.P., Peel, D.A., Sarno, L. (2001): 'Nonlinear Mean-Reversion in Real Exchange Rates: Toward a Solution to the Purchasing Power Parity Puzzles', International Economic Review, 42(4), pp. 1015-1042.

Turnovsky, S. J., Fisher, W. H. (1995): 'The composition of government expenditure and its consequences for macroeconomic performance', Journal of Economic Dynamics and Control, 19, pp. 747-786.

Turnovsky, S.J. (2004): 'The transitional dynamics of fiscal policy: longrun capital accumulation and growth', Journal of Money, Credit, and Banking, 36, pp. 883-910. 


\section{Appendix A}

In order to find the wage locus, we first have to express $L_{N}$ as a function of $L_{T}$. Using equation (12), along with substituting from (11) and defining profits and rents as a function of wages, we obtain:

$$
\frac{P_{N} C_{N}}{1-\phi}=W\left(L_{T}+L_{N}\right)+(1-s)\left(1-\tau_{T}\right) \frac{\alpha}{1-\alpha} W L_{T}+(1-s) \frac{1-\sigma}{\sigma} W L_{N}
$$

Substituting from (9) and imposing the market clearing condition from (13), we obtain:

$$
L_{N}=\lambda L_{T}
$$

where $\lambda \equiv \frac{\left[\frac{1+\alpha(s \tau-s-\tau)}{1-\alpha}\right]}{\left[\frac{1}{\sigma(1-\phi)}-1-\frac{(1-s)(1-\sigma)}{\sigma}\right]}$. Assuming a sufficiently large share of nontradable goods in total consumption $(\phi)$ and a sufficiently large saving rate $(s), \lambda$ is more likely to be positive. In turn, a rise in the demand for labor in the tradable sector has a positive impact in the demand for labor in the non-tradable sector.

We now need to find $\hat{w}_{N}$. In order to find it, we recall from (8) that:

$$
w_{N}=\sigma B L_{N}^{\sigma-1}
$$

Substitution of (23) into (24) yelds: 


$$
w_{N}=\sigma B\left[\lambda(1-\tau) \tau^{\frac{\chi}{\alpha}}\left(\frac{(1-\alpha)}{w_{T}}\right)^{\frac{1}{\alpha}} K^{\frac{\chi+\alpha}{\alpha}}\right]^{\sigma-1}
$$

Taking natural logs, differentiating with respect to time and considering that $\hat{W}=\hat{w}_{T}$ (since $P_{T}$ is constant), and using equations (16)-(19), we obtain:

$$
\hat{W}=\frac{1}{\rho \phi}\left\{\frac{w^{d}-w}{w}-(1-\phi)\left[\frac{(\alpha+\chi)(\sigma-1)}{\alpha} \hat{K}\right]\right\}
$$

where $\rho \equiv\left[1-\frac{(1-\phi)(\sigma-1)}{\phi \alpha}\right]>0$.

Substituting (17) into (26), we obtain:

$$
\hat{W}=\frac{1}{\rho \phi}\left\{\left[\frac{m(1-e)^{-\xi}}{w_{T}^{1-\phi} w_{N}^{\phi}}-1\right]-(1-\phi)\left[\frac{(\alpha+\chi)(\sigma-1)}{\alpha} \hat{K}\right]\right\}
$$

\section{Appendix B: Derivation of the $\hat{w}_{T}=0$ locus}

We already know from (15) that $\left.\frac{\mathrm{d} \log w_{T}}{\mathrm{~d} \log K}\right|_{\hat{K}=0}$ is positively sloped, so that we can focus on the first term of the right hand side of (27) in order to find the $\hat{w}_{T}=0$ locus. In order to do that, we must have:

$$
\frac{w^{d}}{w_{T}^{1-\phi} w_{N}^{\phi}}-1=0
$$

We know from previous equations how each term of (28) varies with $w_{t}$ and $K$. From (25) we know that $w_{N}$ rises with $w_{T}$ and falls with $K$. From (7), (17), and (23) we know that $w^{d}$ rises with $K$ and falls with $w_{T}$. Equation 
(28) can thus be expressed as an implicit function on $\mathrm{K}, w_{T}$ and $\tau$ :

$$
G\left(K, w_{T}, \tau\right)=w^{d} w_{T}^{\phi-1} w_{N}^{-\phi}-1=0
$$

Hence, we find that:

$$
\frac{\partial w_{T}}{\partial K}=-\frac{w_{T}^{\phi-1}\left[-\phi w_{N}^{-\phi-1} w_{N_{K}} w^{d}+w_{N}^{-\phi} w_{K}^{d}\right]}{\left[(\phi-1) w_{T}^{\phi-2} w_{N}^{-\phi}-\phi w_{T}^{\phi-1} w_{N}^{-\phi-1} w_{N_{w_{T}}}\right] w^{d}+w_{T}^{\phi-1} w_{N}^{-\phi} w_{w_{T}}^{d}}>0
$$

Since $w_{N_{K}}<0, w_{N_{w_{T}}}>0, w_{w_{T}}^{d}<0$, and $w_{K}^{d}>0$, we find that the expression in (30) is strictly positive, i.e., the expression $w^{d}=w_{T}^{1-\phi} w_{N}^{\phi}$ is positively sloped, so that the $\hat{w}_{T}=0$ locus is also positively sloped.

\section{Appendix C: Multiple Equilibria}

Consider first the the $\hat{K}=0$ locus. From (14), we know that the condition is that $r=i+\delta$. Substituting it into (15), taking logs and totally differentiating, we obtain:

$$
\frac{\mathrm{d} \log w_{T}}{\mathrm{~d} \log K}=\frac{\chi}{1-\alpha}
$$

To find the locus of the expression $w^{d}=w_{T}^{1-\phi} w_{N}^{\phi}$, we need to substitute (17) and (25) into (29). Taking logs and totally differentiating,

$$
\frac{\mathrm{d} \log K}{\mathrm{~d} \log w_{T}}=(\chi+\alpha) \frac{\phi(1-\sigma)+\xi \frac{e}{1-e}}{\alpha(1-\phi)+(1-\sigma) \phi+\xi \frac{e}{1-e}}
$$


Multiple equilibria will arise when these two locus intercept more than once. As we can see from (32), the locus is not constant, and in fact depends on the employment rate, as $K$ varies. From (7) and (23) we can see how the employment rate responds to a variation in $K$. We have two cases:

(1) As $\mathrm{K} \rightarrow \infty$, the locus is:

$$
\frac{\mathrm{d} \log K}{\mathrm{~d} \log w_{T}}=\chi+\alpha
$$

(2) As $\mathrm{K} \rightarrow 0$, the locus is:

$$
\frac{\mathrm{d} \log K}{\mathrm{~d} \log w_{T}}=(\chi+\alpha) \frac{\phi(1-\sigma)}{\alpha(1-\phi)+(1-\sigma) \phi}
$$

For the first case, the slope of the expression $w^{d}=w_{T}^{1-\phi} w_{N}^{\phi}$ will be greater than the slope of $\hat{K}=0$ if and only if:

$$
\chi+\alpha<1
$$

In the latter case, already assuming the previous condition, the slope of the expression $w^{d}=w_{T}^{1-\phi} w_{N}^{\phi}$ will be smaller than the slope of $\hat{K}=0$ if:

$$
\frac{\chi}{1-\alpha}>\frac{\phi(1-\sigma)}{\alpha(1-\phi)+(1-\sigma) \phi}
$$

The first condition states that the positive effect of the flow of provision of public infrastructure needs to be sufficiently low, otherwise the model 
dynamic would be explosive. The second condition, similarly to the model in Rapetti (2013), is intuitively more likely to hold the higher are the values of $\alpha, \sigma$ and $\phi$, i.e., the more capital intensive is the tradable production, the more elastic is the supply of non-tradables and the higher is the share of tradables in private consumption. Our following analysis will assume that both conditions hold. 


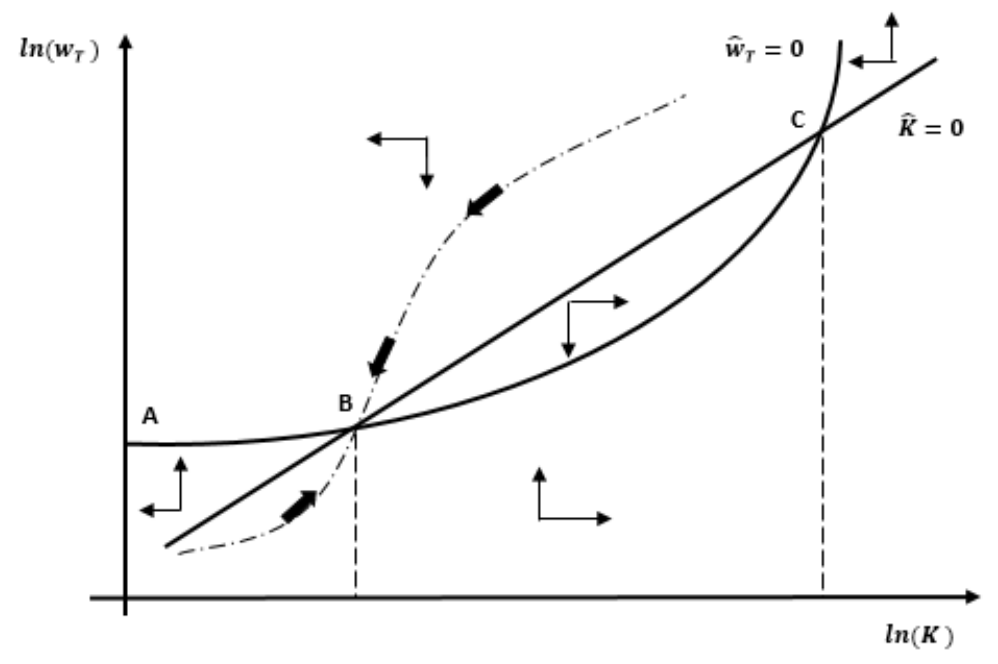

Fig. 1: Model in $(\ln W, \ln K)$ space

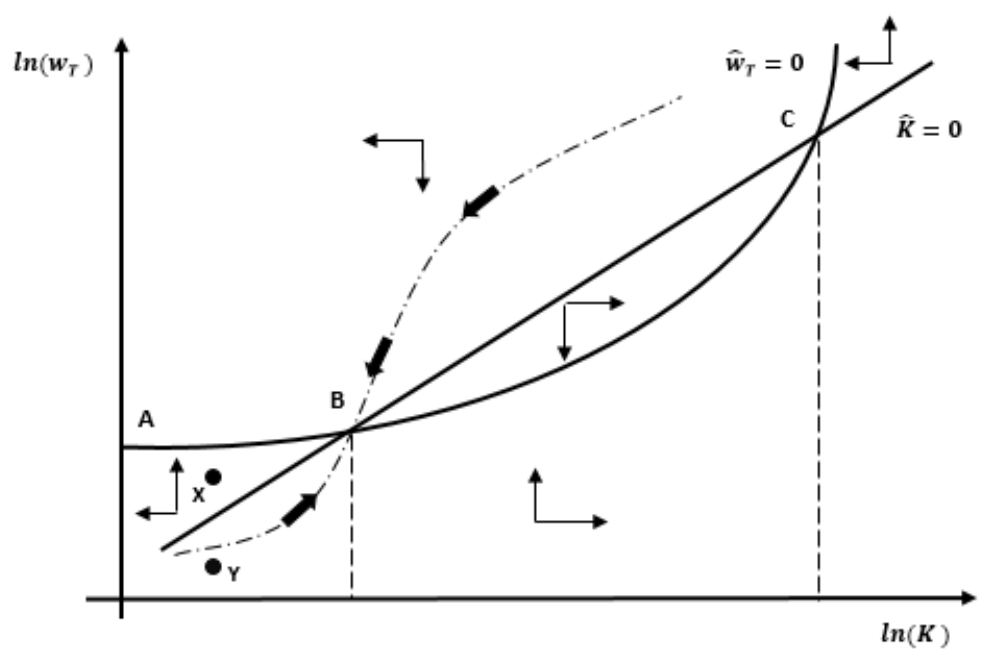

Fig. 2: Exchange rate policy 


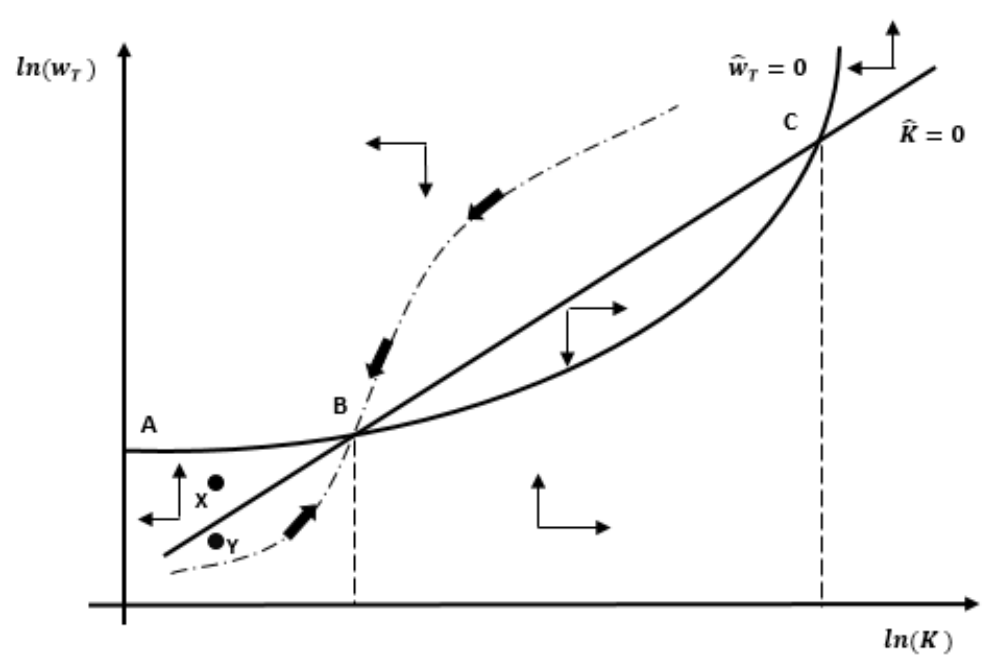

Fig. 3: Exchange rate policy: the case of an insufficient devaluation

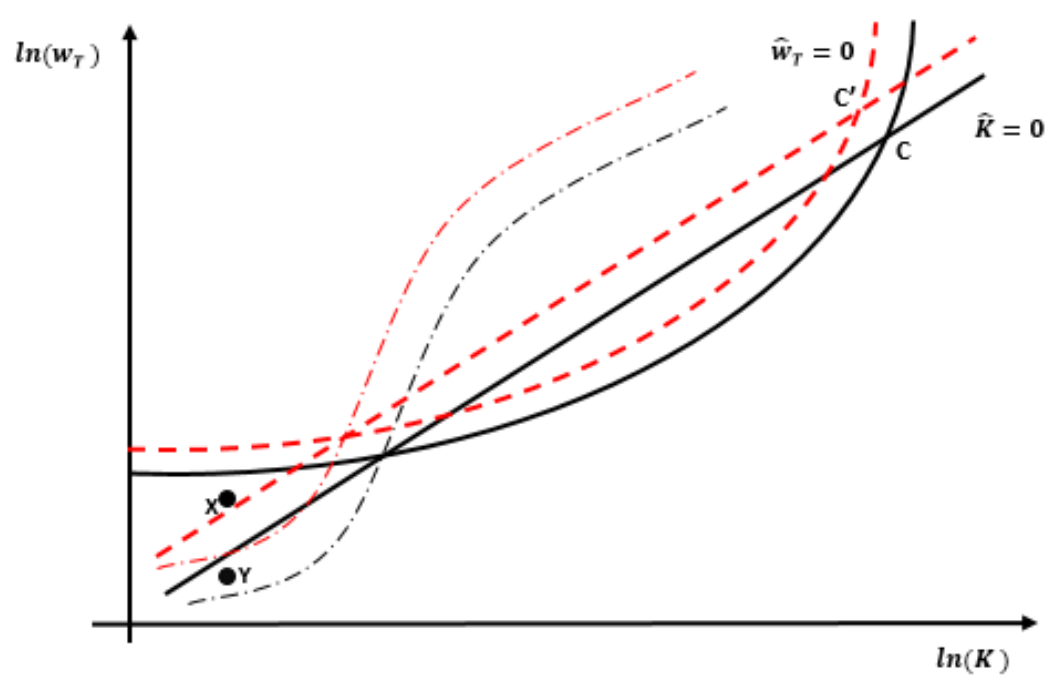

Fig. 4: The role of public infrastructure 


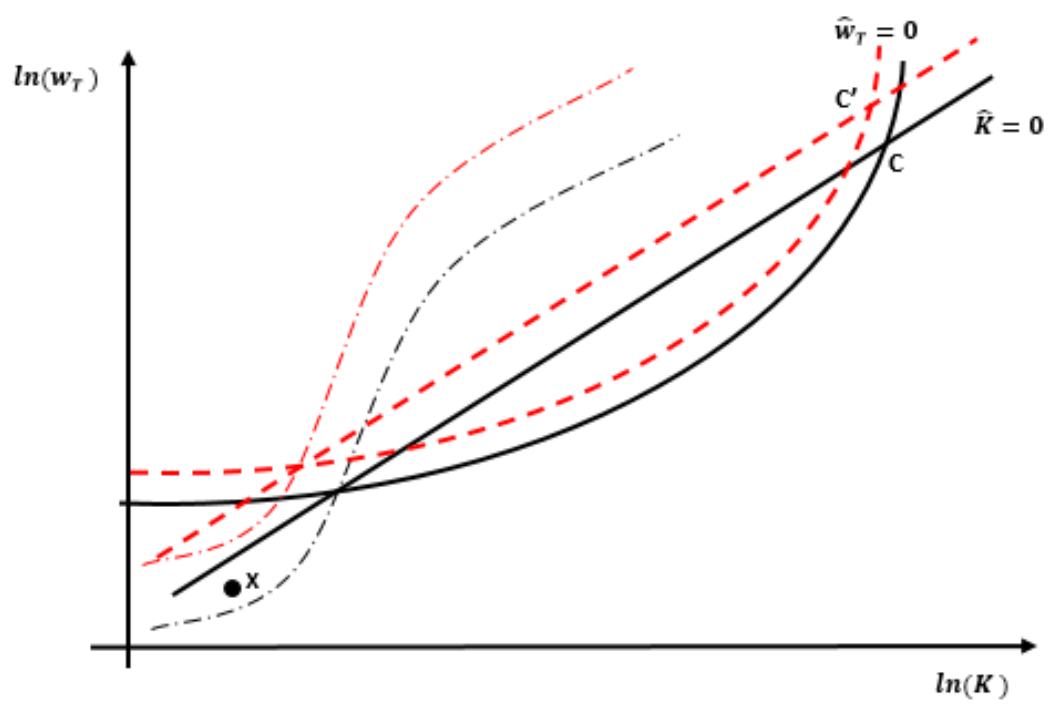

Fig. 5: Public infrastructure policy separately

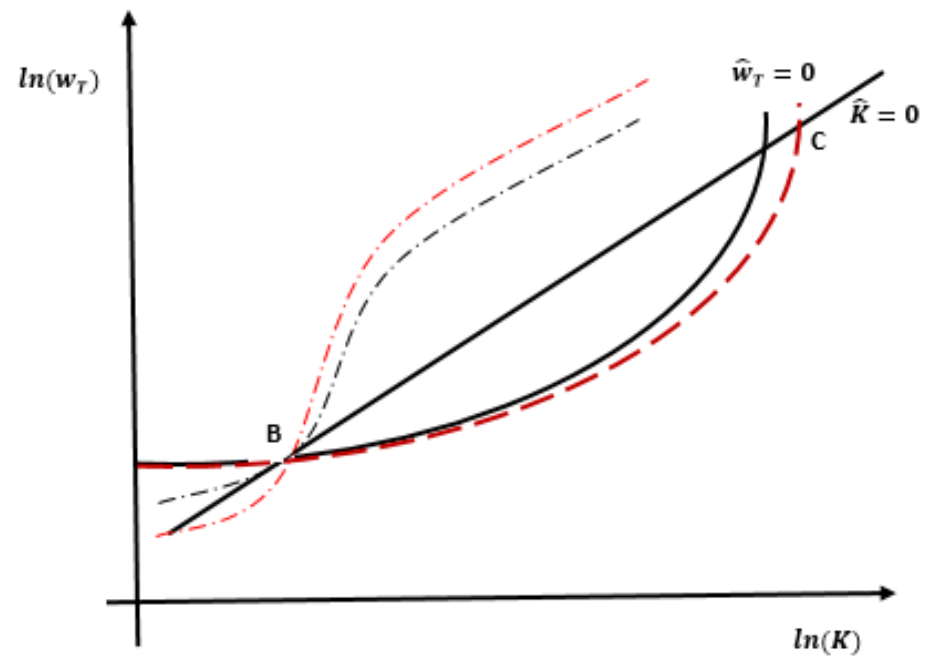

Fig. 6: Public infrastructure and inflation 